\title{
Unusual Infrared Spectrum of Ethane Adsorbed by Gallium Oxide
}

\author{
V.B. Kazansky*a, I.R. Subbotina ${ }^{\mathrm{a}}$, A.A. Pronin ${ }^{\mathrm{a}}$, R. Schlögl ${ }^{\mathrm{b}}$, F.C. Jentoft ${ }^{\mathrm{b}}$ \\ a'Zelinsky Institute of Organic chemistry, Leninsky prospect 47, Moscow 119991, Russia \\ ${ }^{b}$ Department of Inorganic Chemistry, Fritz-Haber-Institute of the MPG, Faradayweg 4-6, 14195 Berlin, Germany \\ ${ }^{*}$ Corresponding author: e-mail vbk@ioc.ac.ru,
}

Received: 11 October 2005; In Final Form:29 December 2005

\begin{abstract}
The present study reports an unusual diffuse reflection Fourier transform (DRIFT) spectrum of ethane adsorbed by gallium oxide. One of the stretching $\mathrm{C}-\mathrm{H}$ bands in this spectrum with a maximum at $2753 \mathrm{~cm}^{-1}$ is more than by $100 \mathrm{~cm}^{-1}$ shifted toward lower frequencies in comparison with gaseous ethane. In addition, the relative intensity of this band is unusually high. This indicates a very strong polarizability of the corresponding chemical bonds resulting from perturbation of ethane by the low coordinated $\mathrm{Ga}^{3+}$ cations. The assignment of this band to the very strongly perturbed initially fully symmetric $v_{1} \mathrm{C}-\mathrm{H}$ stretching vibration is confirmed by a DFT modeling of ethane adsorption by the simplest $\mathrm{Ga}_{2} \mathrm{O}_{3}$ cluster. The obtained results also indicate heterolytic dissociative adsorption and dehydrogenation of ethane by $\mathrm{Ga}^{3+}$ Lewis sites at elevated temperature. This is evidenced by appearance of new IR bands from gallium alkyl fragments and acidic protons followed by decomposition of resulting gallium ethyl species. In parallel, the most intense IR band at lower frequency from the most strongly polarized C-H chemical bond decreased in intensity. The obtained results indicate that these vibrations are involved in subsequent heterolytic dissociative adsorption. The obtained results demonstrate that, similar to the shifts of C-H stretching vibrations to the low-frequency, intensities of IR C-H stretching bands can be also used as an index of chemical activation of adsorbed paraffins via their polarization by the low-coordinated cations.
\end{abstract}

Keywords: $\mathrm{Ga}_{2} \mathrm{O}_{3}$, diffuse reflection, infrared, ethane adsorption and dehydrogenation, polarization of adsorbed species.

\section{Introduction}

A well-known traditional way for IR spectral control of chemical activation of adsorbed molecules in heterogeneous catalysis is provided by the low-frequency shifts of IR stretching bands. Recently we demonstrated that along with the low - frequency shifts, adsorption of hydrocarbons by cationic forms of zeolites also results in very unusual intensity distribution of the $\mathrm{C}-\mathrm{H}$ stretching bands [1-3]. Therefore, we proposed to use intensities of IR bands in as an additional spectral criterion for activation of adsorbed paraffins. We also believe that this parameter is more directly related to polarization of adsorbed molecules by active sites than the stretching frequencies.

Indeed, according to the fundamentals of IR spectroscopy, intensities of the stretching bans are proportional to the squares of the derivatives of additional dipole moment $d \mu$ created by the stretching of chemical bonds via their vibrations over normal coordinate $q$ of these vibrations [4]:

$$
I \propto[\mathrm{d} \mu / \mathrm{d} \mathrm{Q}]^{2}
$$

In other words, intensities of the IR stretching bands are closely related to additional polarization of chemical bonds resulting from their vibrational excitation.

Information concerning weakening of chemical bonds upon adsorption is traditionally provided by the shifts of the corresponding stretching bands toward lower frequencies. However, these shifts may arise from different mechanisms of chemical activation. For instance, they may be connected with the donor-acceptor bonding, with positive or negative charging of adsorbed molecules, with their polarization by the active sites etc. In this connection, any additional information on the mechanism of perturbation of vibrational modes resulting from adsorption is highly desirable. Such information can be gained from intensities of IR stretching bands.

Indeed, if intensities of IR bands from different vibrational modes change upon adsorption in a different way, this indicates a different polarizability of chemical bonds 
involved in different vibrational modes. Therefore, intensities of IR stretching bands can provide information on anisotropy of polarization of adsorbed molecules upon their vibrational excitation.

Utilization of this additional spectral criterion is obviously most attractive for heterogeneous acid or acid-base catalysis, where the main source of chemical activation is provided by polarization of adsorbed molecules. Therefore, for these kinds of catalytic action, intensities of IR stretching bands are most closely connected with enhancement of reactivity resulting from adsorption. In addition, different distributions of IR stretching bands in intensity created by adsorption may also provide a new explanation for selectivity of acid-catalyzed reactions at the molecular level.

In Refs. [1-3] such new spectral approach was supported by our experimental results on adsorption of methane and ethane by ZSM-5 zeolite modified with $\mathrm{Zn}^{+2}$ cations. In these studies we demonstrated that, at elevated temperatures, the most intense $\mathrm{C}-\mathrm{H}$ vibrations which correspond to the stretching of the highly polarized $\mathrm{C}-\mathrm{H}$ bonds of molecules adsorbed by the coordinatively unsaturated zinc cations are involved into subsequent heterolytic dissociative adsorption via abstraction of protons by the adjacent basic oxygen atoms. This allows concluding that intensities of IR stretching bands could be used as additional reactivity index of chemical activation of adsorbed molecules.

Below we present another example illustrating application of such approach to dissociative adsorption and dehydrogenation of ethane by gallium oxide. For more convincing interpretation of the experimentally observed DRIFT spectra, positions and intensities of the IR bands were compared with results of DFT modeling of ethane adsorption by the low-coordinated $\mathrm{Ga}^{+3}$ ions in the simplest $\mathrm{Ga}_{2} \mathrm{O}_{3}$ cluster.

\section{Experimental}

$\mathrm{Ga}_{2} \mathrm{O}_{3}$ was obtained by calcination of gallium nitrate at $773 \mathrm{~K}$ for $12 \mathrm{~h}$ in flowing air. DRIFT spectra of ethane adsorbed by the grains pressed from the $\mathrm{Ga}_{2} \mathrm{O}_{3}$ powder were recorded at room temperature in a quartz optical cell with a $\mathrm{CaF}_{2}$ window. Samples touched the window. Therefore the beam path through the gas phase was limited to the void space within the catalyst bed, and gas phase contributions into IR spectra were minimized. Similar to our previous studies [1-3], DRIFT spectra were taken using a Nicolet "Impact 410" spectrophotometer equipped with a home-made diffuse reflectance attachment. $\mathrm{CaF}_{2}$ powder was used for background measurements. Spectra with $4 \mathrm{~cm}^{-}$ ${ }^{1}$ resolution were processed with OMNIC ${ }^{\mathrm{TM}}$ software. For all spectra, the reflectance with respect to $\mathrm{CaF}_{2}$ was converted into Kubelka-Munk units, setting the reflectance at $5000 \mathrm{~cm}^{-1}$ to a value of 0.9 . Before spectral measurements, the samples were pretreated in vacuum for $2 \mathrm{~h}$ at $773 \mathrm{~K}$.

Ethane adsorption was carried out at room temperature at different equilibrium pressures. In some experiments the samples were preheated in ethane atmosphere at ele- vated temperatures, while the DRIFT spectra were recorded after cooling the samples to room temperature. Prior to adsorption, ethane was purified by the triple vacuum distillation after freezing at $77 \mathrm{~K}$. After Kubelka-Munk transformations the background created by the granulated $\mathrm{Ga}_{2} \mathrm{O}_{3}$ was subtracted from DRIFT spectra of the samples with adsorbed ethane.

The Gradient-corrected Density Functional Theory (DFT) modeling of ethane adsorption by the lowcoordinated $\mathrm{Ga}^{+3}$ cations was performed for the simplest $\mathrm{Ga}_{2} \mathrm{O}_{3}$ cluster shown in Fig. 6. The calculations were carried out using the GAUSSIAN-03 program [5] with the hybrid B3LYP functional that gives acceptable values for molecular energies and geometries [6]. All calculations were carried out using standard 6-31G [7] basis set for all atoms of the cluster and adsorbed ethane species. The optimization of geometry was at first carried out for an isolated $\mathrm{Ga}_{2} \mathrm{O}_{3}$ cluster and then for all atoms of the cluster and adsorbed ethane. The scaling factor for the calculated $\mathrm{C}-\mathrm{H}$ stretching frequencies was taken as 0.96 .

\section{Results and Discussion}

DRIFT spectra of ethane adsorbed by the granulated $\mathrm{Ga}_{2} \mathrm{O}_{3}$ sample with particle size of ca. $0.5-1 \mathrm{~mm}$ recorded at different equilibrium pressures are shown in Fig. 1. They correspond to the superposition of the bands from three different forms of ethane adsorption, while at low pressure the contribution of gaseous ethane into the entire DRIFT spectra can be ignored due to the small volume of the gas between $\mathrm{Ga}_{2} \mathrm{O}_{3}$ particles (See in this connection Ref. [8] where our technique is described in more detail). The stronger forms of adsorption obviously predominate at lower pressures, while the weaker forms can be more easily removed by evacuation at room temperature.

Indeed, as follows from Fig. 1, intensities of some of the narrow bands at higher frequencies decrease upon lowering of ethane pressure more rapidly than of the broad band at $2753 \mathrm{~cm}^{-1}$. Therefore, they belong to the weaker form, while the broad band to the stronger form of molecular adsorption. On the other hand, some of the narrow bands remain visible even after evacuation of ethane for 5 minutes. This indicates that they belong to the strongest form which corresponds to dissociative adsorption.

This conclusion follows from Fig. 2, which indicates that after heating of the $\mathrm{Ga}_{2} \mathrm{O}_{3}$ sample in an ethane atmosphere above $423 \mathrm{~K}$ and subsequent evacuation of ethane at room temperature, the intensities of the narrow $\mathrm{C}-\mathrm{H}$ stretching bands at 2876, 2915 and $2952 \mathrm{~cm}^{-1}$ strongly increased. Simultaneously, new DRIFTS bands appear in the $\mathrm{OH}$ stretching region at of 3620 and $3633 \mathrm{~cm}^{-1}$ (Fig. 3). This should be explained by heterolytic dissociative adsorption of ethane on the acid-base pairs composed of low coordinated $\mathrm{Ga}^{+3}$ ions and adjacent basic oxygen atoms: 


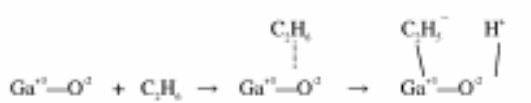

Taking into account that such dissociative adsorption occurs in parallel with the intensity decrease of the broad $\mathrm{C}-\mathrm{H}$ band from the stronger form of molecular adsorption, one may suggest that the latter plays the role of a precursor for the dissociative adsorption. Thus, the DRIFT spectrum (3) in Fig. 1, that was recorded at the lowest ethane pressure, corresponds to superposition of the bands from the dissociative adsorption and the stronger form of molecular adsorption.

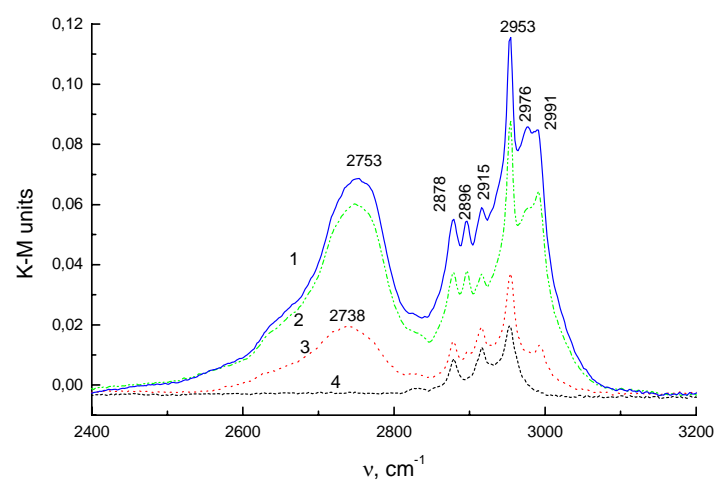

Figure 1: DRIFT spectra of ethane adsorbed at room temperature by $\mathrm{Ga}_{2} \mathrm{O}_{3}$ grains at different pressures: (1) - 8.6 torr; (2) - 5 torr ; (3) - 0.4 torr; 4 - the DRIFT spectrum was recorded after evacuation of ethane at $300 \mathrm{~K}$ for $5 \mathrm{~min}$.

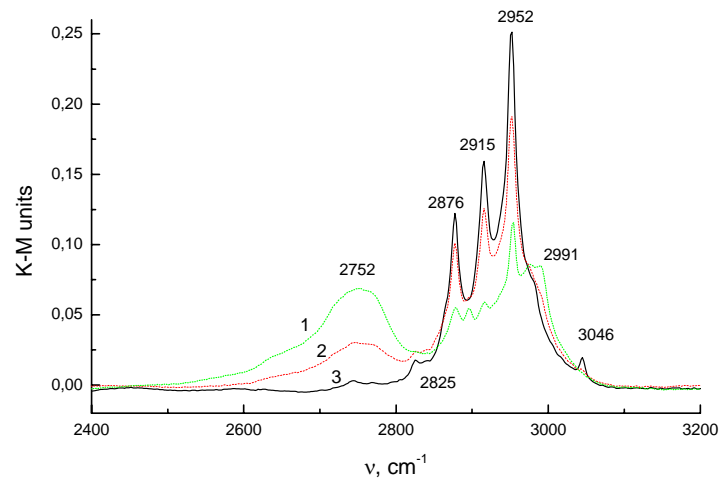

Figure 2: DRIFT spectra of ethyl - gallium species resulting from the dissociative adsorption of ethane after heating of $\mathrm{Ga}_{2} \mathrm{O}_{3}$ in ethane atmosphere at the pressure of 8.6 torr at the following temperatures: (1) $-300 \mathrm{~K} ;(2)-423 \mathrm{~K}$; (3) $-473 \mathrm{~K}$. The spectra were recorded at room temperature.

To obtain the individual spectrum of the stronger molecular form, we subtracted the spectrum (4) in Fig. 1 from the spectrum (3). The resulting spectrum of the stronger form of molecular adsorption is shown in Fig. 4. It is represented by the broad strongly low-frequency shifted band with a maximum at $2737 \mathrm{~cm}^{-1}$ and three much weaker narrow bands with positions that are very close to those characteristic of dissociative adsorption.

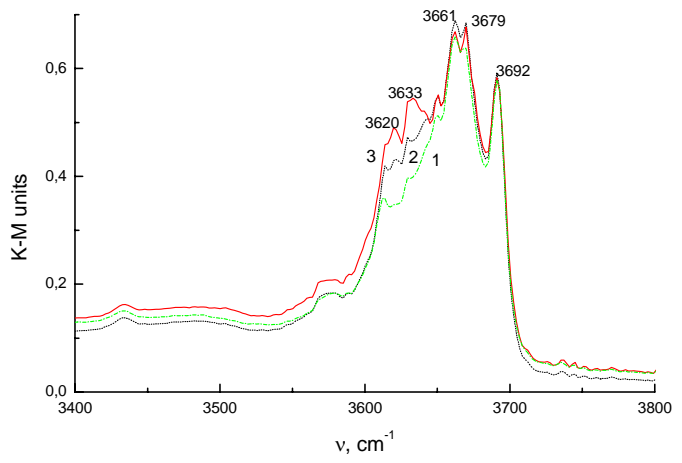

Figure 3: DRIFT spectra of $\mathrm{OH}$ groups after heating of $\mathrm{Ga}_{2} \mathrm{O}_{3}$ in ethane atmosphere at different temperatures at the pressure of 8.6 torr: (1) - 300; (2) - 423 and (3) - $473 \mathrm{~K}$.

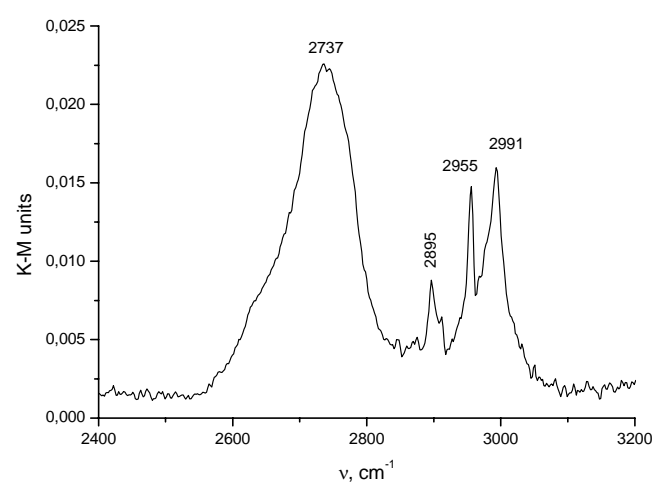

Figure 4: DRIFT spectrum of the stronger molecular form of ethane adsorption on $\mathrm{Ga}_{2} \mathrm{O}_{3}$ obtained by subtracting of the spectrum (4) in Fig. 1 from the spectrum (3).

The very intense and very strongly shifted toward low-frequency broad $\mathrm{C}-\mathrm{H}$ stretching band in this spectrum is quite remarkable. The large shift of this band toward low-frequency indicates a very strong perturbation of adsorbed ethane. On the other hand, the very high relative intensity of this band in comparison with the other $\mathrm{C}-\mathrm{H}$ stretching bands indicates extremely high polarizability of the bonds involved in the corresponding vibration. Obviously, the perturbation and polarization of the other $\mathrm{C}-\mathrm{H}$ bonds are much weaker. These results are similar to those earlier reported in our study [2] on ethane adsorption by $\mathrm{Zn}^{+2}$ ions in ZnZSM-5 zeolite, where it was also shown that polarization of adsorbed molecules was followed by heterolytic dissociative adsorption at elevated temperatures.

The results of DFT modeling of ethane adsorption by the simplest $\mathrm{Ga}_{2} \mathrm{O}_{3}$ cluster are presented in Fig. 5 and Table 1. They indicate that molecular adsorption of ethane occurs via bonding of two protons of one of the methyl groups by the low-coordinated $\mathrm{Ga}^{+3}$ ion. The calculated adsorption heat of $16 \mathrm{kcal} / \mathrm{mol}$ is in agreement with the moderately strong adsorption. The results of quantum chemical modeling also reasonably well reproduce appearance of the symmetry forbidden $\mathrm{C}-\mathrm{H}$ stretching bands due 
to the lowering upon adsorption of the symmetry of ethane. They also well explain unusually high intensity of the band from initially symmetric $v_{1}$ vibrations which are very strongly perturbed by interaction with low coordinated $\mathrm{Ga}^{+3}$ ions (Fig. 5). Comparison of the calculated and experimentally measured IR stretching frequencies in Table 1 also demonstrates a reasonably good agreement between these values even for the simplest cluster.

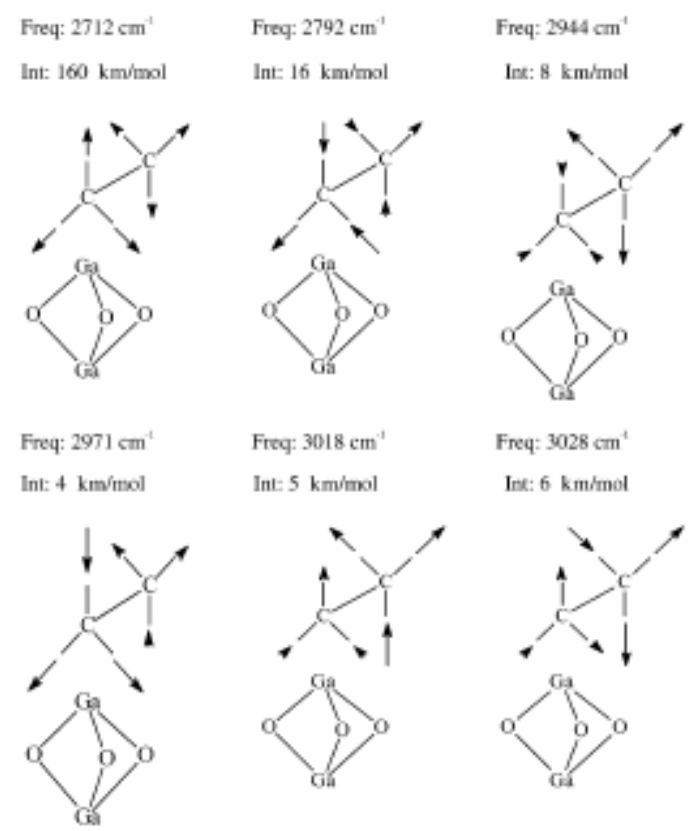

Figure 5: The frequencies and intensities of the DFT calculated $\mathrm{C}-\mathrm{H}$ vibrational stretching modes of ethane adsorbed by the model $\mathrm{Ga}_{2} \mathrm{O}_{3}$ cluster.

Table 1: Comparison of the calculated frequencies of stretching $\mathrm{C}-\mathrm{H}$ vibrations of ethane adsorbed by $\mathrm{Ga}_{2} \mathrm{O}_{3}$ with the figures experimentally obtained from IR spectra.

\begin{tabular}{cc}
\hline $\begin{array}{c}\text { Experimental frequencies, } \\
\mathrm{cm}^{-1}\end{array}$ & $\begin{array}{l}\text { Calculated frequencies, } \\
\mathrm{cm}^{-1}\end{array}$ \\
\hline & \\
2737 & 2712 \\
- & 2792 \\
2895 & 2944 \\
2955 & 2971 \\
- & 3018 \\
2991 & 3028 \\
\hline
\end{tabular}

Thus, even a very crude modeling of the low coordinated $\mathrm{Ga}^{+3}$ ions, explains reasonably well our experimental results, while the unusually high intensity of the broad band from the initially fully symmetric $v_{1}$ stretching vibrations very strongly perturbed by adsorption indicates extremely high polarizability of the corresponding chemical bonds. Therefore, it is nothing surprising, that according to the DRIFT spectra shown in Fig. 2, the stronger form of molecular adsorption is involved into subsequent heterolytic dissociation of ethane at elevated temperatures. As follows from spectrum (4) in Fig. 1, the dissociative adsorption in a very low extent starts already at room temperature, whereas according to Fig. 2 at higher temperatures, the intensities of IR bands from the ethyl-gallium species become much stronger.

The mechanism of the unusually easy heterolytic dissociative adsorption of ethane could be most likely described in the following way. The initial adsorption of ethane by the coordinatively unsaturated gallium cations leads to different polarizability of different $\mathrm{C}-\mathrm{H}$ bonds. The highest intensity of the low frequency C-H IR stretching band points to the highest extent of polarizability of thel bonds involved in the corresponding vibrations. Due to redistribution of electron density between carbon and hydrogen atoms in the methyl group closely contacting the gallium cation, the calculated positive Mulliken charges for these hydrogen atoms increase to $+0.224 \mathrm{e}$ in comparison with only +0.105 e for a free ethane molecule. In addition, such polarization also results in the higher negative charge of carbon atom (the calculated Mulliken charges are equal to -0.315 e for free ethane molecule and to -0.492 e for the adsorbed ethane, respectively).

Due to subsequent vibrational excitation, polarization of $\mathrm{C}-\mathrm{H}$ bonds in the methyl group contacting gallium cation increases. This results in subsequent abstraction of proton by the adjacent oxygen atom of the cluster with simultaneous formation of a new carbon-gallium bond.

The occurrence of heterolytic dissociative adsorption already at room temperature implies a low activation barrier. This well agrees with high polarizability of $\mathrm{C}-\mathrm{H}$ bonds most strongly perturbed by adsorption. Therefore, upon subsequent excitation to higher vibrational levels polarization of these bonds increases. This in turn results in even stronger interaction of adsorbed ethane with the gallium active site and in even stronger polarizability and polarization of the $\mathrm{C}-\mathrm{H}$ bonds most closely contacting $\mathrm{Ga}^{+3}$ cation. Development of such self-consistent process corresponds to the motion of adsorbed ethane along the reaction coordinate of heterolytic dissociative adsorption. The latter most likely corresponds to a combination of the stretching vibration of $\mathrm{C}-\mathrm{H}$ bonds with the bending vibration of adsorbed ethane which brings one of the protons closer to adjacent basic oxygen atom of the cluster. The mutual influence of the stronger adsorption and increasing selective polarization of the corresponding $\mathrm{C}-\mathrm{H}$ stretching bonds explains dissociative adsorption of ethane at low temperature.

Figure 6 shows that heterolytic dissociative adsorption of ethane at higher temperatures is accompanied by the formation of gallium hydrides via subsequent decomposition of resulting gallium-ethyl species. Formation of hydrides is evidenced by appearance of the IR band with a stretching frequency of $1969 \mathrm{~cm}^{-1}$ with a high frequency shoulder at $1981 \mathrm{~cm}^{-1}$. These frequencies are close to 1976 and $1993 \mathrm{~cm}^{-1}$ reported in Ref. [9] for $\mathrm{Ga}_{2} \mathrm{H}_{6}$ vapor. As follows from Fig. 6, decomposition of ethyl fragments starts above $423 \mathrm{~K}$, while the comparison of Figs. 2 and 6 reveals that, in temperature interval of 423-473 K, heterolytic dissociative adsorption and decomposition of ethyl fragment occurs in parallel. This obviously indicates dehy 


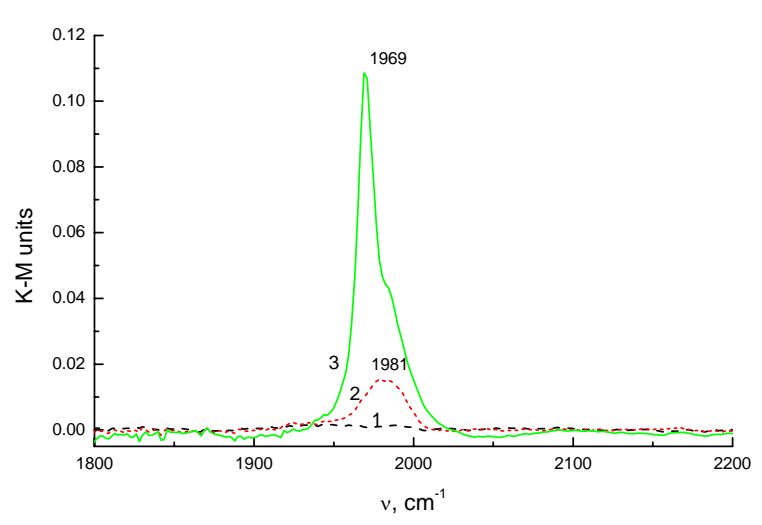

Figure 6: DRIFT spectra of gallium hydrides resulting from heating of $\mathrm{Ga}_{2} \mathrm{O}_{3}$ in ethane atmosphere at different temperatures at the pressure of 8.6 torr. (1) - $300 \mathrm{~K}$; (2) $423 \mathrm{~K}$ and (3) - $473 \mathrm{~K}$.

drogenation of adsorbed ethyl species which is also confirmed by appearance of the weak $\mathrm{C}-\mathrm{H}$ stretching band at $3046 \mathrm{~cm}^{-1}$ that should be ascribed to the stretching vibrations of $\mathrm{CH}_{2}$ groups in resulting ethylene (Fig. 2).

Thus, the above results present another example of utilization of intensities of IR stretching bands as an additional spectral criterion of chemical activation of adsorbed light paraffins via their polarization by Lewis acid active sites. The advantage of this approach in comparison with the shifts of C-H stretching bands to the low frequencies consists in more direct connection of intensities with polarizability of adsorbed molecules. In addition, the intensi-

\section{References}

[1] Kazansky, V. B.; Serykh, A. I.; Pidko, E. A. J.Catal. 2004, 225, 369.

[2] Kazansky, V.B.; Pidko, E. A. J. Phys. Chem. B 2005, 109, 2103.

[3] Shubin, A. A.; Zhidomirov, G. M.; Kazansky V.B. and van Santen, R.A. Catal. Lett. 2003, $90,137$.

[4] Herzberg, G. Molecular Spectra and Molecular Structure. II. Infrared and Raman Spectra of Polyatomic Molecules; New York, D. Van Nostrand Company inc., 1947.

[5] Frisch, M. J.; Trucks, G. W.; Schlegel, H. B.; Scuseria, G. E.; Robb, M. A.; Cheeseman, J. R.; Montgomery, J. A.; Vreven, Jr. T.; Kudin, K. N.; Burant, J. C.; Millam, J. M.; Iyengar, S. S.; Tomasi, J.; Barone, V.; Mennucci, B.; Cossi, M.; Scalmani, G.; Rega, N.; Petersson, G. A.; Nakatsuji, H.; Hada, M.; Ehara, M.; Toyota, K.; Fukuda, R.; Hasegawa, J.; Ishida, M.; Nakajima, T.; Honda, Y.; Kitao, O.; Nakai, H.; Klene, M.; Li, X.; Knox, J. E.; Hratchian, H. P.; Cross, J. B.; Adamo, C.; Jaramillo, J.; Gomperts, R.; Stratmann, R. E.; Yazyev, O.; Austin, A. J.; Cammi, R.; Pomelli, C.; Ochterski, J. W.; Ayala, P. Y.; Morokuma, K.; Voth, G. A.; Salvador, P.; Dan- ties of IR stretching bands better reproduce the tendency of adsorbed molecules for their subsequent polarization and activation via vibrational excitation, while the shifts of IR bands to the lower frequencies are related to perturbation of the ground states of adsorbed molecules.

In conclusion, we would like to emphasize, that intensities of IR stretching bands have been already for a long time utilized for analysis of charge distribution and polarization of simple molecules or of $\mathrm{C}-\mathrm{H}$ stretching bonds in hydrocarbons and their derivates (see for instance Refs. [10] and [11] ). However, prior to our works, this has been never done for adsorbed hydrocarbons.

\section{Acknowledgements}

The authors express their thanks for financial support to the Russian Foundation for Basic Research (the Grant № 04-03-04001), the DFG (project № 436 RUS 113/778/0-1), to the Program of the President of the Russian Federation (the project № 1745.2003.3) and to the Program of Department of Chemistry and Material Sciences of the Russian Academy of Sciences "Theoretical and experimental study of nature of chemical bonds and of most important chemical reactions and processes"

nenberg, J. J.; Zakrzewski, V. G.; Dapprich, S.; Daniels, A. D.; Strain, M. C.; Farkas, O.; Malick, D. K.; Rabuck, A. D.; Raghavachari, K.; Foresman, J. B.; Ortiz, J. V.; Cui, Q.; Baboul, A. G.; Clifford, S.; Cioslowski, J.; Stefanov, B. B.; Liu, G.; Liashenko, A.; Piskorz, P.; Komaromi, I.; Martin, R. L.; Fox, D. J.; Keith, T.; Al-Laham, M. A.; Peng, C. Y.; Nanayakkara, A.; Challacombe, M.; Gill, P. M. W.; Johnson, B.; Chen, W.; Wong, M. W.; Gonzalez, C. and Pople, J. A. Gaussian 0 3; Revision B.01; Gaussian, Inc.: Pittsburgh PA, 2003.

[6] Becke, A. D. Phys. Rev. 1988, A38, 3098.

[7] Gordon, M. S. Chem. Phys. Lett. 1980, 76, 163

[8] Kazansky, V. B.; Subbotina, I. R.; van Santen, R. A.; Hensen, E. J. M. J. Catal. 2004, 227, 263.

[9] Pulham, C. R.; Downs, A. J.; Goode, M. J.; Rankin D. W. H. and Robertson, H. E. J. Am. Chem. Soc. 1991, 113, 5149.

[10] Gussoni, M.; Castiglioni, C. J. Molec. Struct. 2000, 521, 1

[11] Galabov, B.; Dudev, T.; Ilieva, S. Spectrochemica Acta 1995, $51 A, 739$ 